PDFlib PLOP: PDF Linearization, Optimization, Protection

Page inserted by evaluation version www.pdflib.com - sales@pdflib.com 


\title{
Sweetened carbonated drinks do not alter upper digestive tract physiology in healthy subjects
}

\author{
R. CUOMO, ${ }^{\star}$ M. F. SAVARese, ${ }^{\star}$ G. SARNelli, ${ }^{\star}$ G. VOllono, ${ }^{\star}$ A. ROCCO, ${ }^{\star}$ P. COCCOli, ${ }^{\star}$ C. CiRILlO,${ }^{\star}$ L. ASCIORE, ${ }^{\star}$ \\ G. NARDONE* \& M. BUYCKX† \\ ${ }^{\star}$ Gastroenterology Unit, Department of Clinical and Experimental Medicine, University of Naples, Naples, Italy \\ $\dagger$ The Beverage Institute for Health \& Wellness, L.L.C., Atlanta, GA, USA
}

\begin{abstract}
Sweetened carbonated beverages are widely consumed, which has fuelled several conflicting opinions about their effects on upper digestive tract functions. We aimed to evaluate the effect of sweetened carbonated drinks, consumed with a standard meal, on gastro-oesophageal reflux, gastric emptying and gallbladder contraction and postmeal sensations in healthy subjects. Thirteen healthy volunteers (seven women, six males; median age 22 years) were tested following the intake of $300 \mathrm{~mL}$ sweetened water containing increasing concentrations of carbon dioxide (seven subjects), and of $300 \mathrm{~mL}$ sweetened commercial flavoured drink with and without carbon dioxide (six subjects). Gastro-oesophageal reflux, gastric emptying and gallbladder contraction were studied by $\mathrm{pH}$-impedance, octanoic acid breath test and ultrasound respectively. Gastro-oesophageal refluxes were significantly increased $1 \mathrm{~h}$ after meal with both water and commercial beverages; only sweetened water without carbon dioxide determined a persistently increasing number of refluxes $2 \mathrm{~h}$ postmeal. No differences were found for gastric emptying, gallbladder contraction or postmeal symptoms with any of the beverages tested. This study shows that $300 \mathrm{~mL}$ of sweetened carbonated beverage with different levels of carbonation or a commercial soft drink do not modify the physiology of the upper digestive tract.
\end{abstract}

Keywords carbon dioxide, carbonated drinks, gastric emptying, gastric sensations, gastro-oesophageal reflux.

Address for correspondence

Professor Rosario Cuomo, Gastroenterology Unit, Department of Clinical and Experimental Medicine, University of Naples

'Federico II', Via Sergio Pansini, 5, 80131 Napoli, Italy.

Tel/fax: +39 081 7463892;

e-mail: rcuomo@unina.it

Received: 12 November 2007

Accepted for publication: 15 January 2008

\section{BACKGROUND}

Carbon dioxide is a gas naturally present in our atmosphere. Commercially, it is added to water to confer the typical bubbling or effervescence that characterizes all carbonated soft drinks. Today, sweetened carbonated beverages are widely consumed, which has fuelled several conflicting opinions about their effect on gastrointestinal (GI) functions. Indeed, several gastroenterologists and general practitioners advise patients with GI diseases to avoid carbonated drinks, particularly in case of gastro-oesophageal reflux disease and dyspepsia. ${ }^{1-5}$ However, some observations have suggested that various beverages differ in terms of their effects on satiety and food intake. ${ }^{6}$

Gastric fundus distension appears mainly involved in the feeling of satiety in healthy individuals, but particularly in dyspeptic patients. The carbon dioxide contained in these beverages could modify gastric volume, consequently inducing a feeling of epigastric discomfort. Hence, carbonated drinks could worsen early satiety in dyspeptic patients. Distension of gastric fundus can also be involved in gastro-oesophageal reflux by increasing transient lower oesophageal sphincter (LOS) relaxation. ${ }^{7}$ Moreover, there is an evidence that carbonated beverages reduce the pressure of the LOS, although few information on reflux activity is available. ${ }^{8,9}$

Despite the allegedly adverse effects on upper digestive tract functions, this matter has been poorly investigated, leaving unanswered many questions regarding the effect of sweetened carbonated drinks on gastro-oesophageal reflux activity, and stomach and gallbladder motility. The changes induced on postprandial sensations by their ingestion during meals are another intriguing issue. In a previous study, we showed improved dyspepsia symptoms after 15 days drinking carbonated water during the day. ${ }^{10}$ In this study, we also found an improved gallbladder function. In addition, we hypothesized that the effect

(c) 2008 The Authors 
on symptoms could be partially associated with a possible modification of visceral sensitivity induced by carbon dioxide influencing perception of symptoms in dyspeptic subjects.

Data regarding the effects of carbon dioxide contained in beverages on stomach function are also conflicting. More than 50 years ago Greenberg and Turner ${ }^{11}$ found that carbonated water accelerated the gastric emptying of a test meal. More recently, another study showed that carbonated water consumed during a meal determined a food distribution in the stomach that favoured gastric emptying and led to an increased sensation of effective digestion. ${ }^{12}$ On the other hand, a study conducted on subjects who underwent mild exercise, showed that the ingestion of a carbonated beverage did not affect the rate of gastric emptying. ${ }^{13}$ Moreover, in the same study the authors also found that the addition of flavourings to carbonated water reduced gastric emptying by as much as $25 \%$.

In this study, we aimed to evaluate gastro-oesophageal refluxes, using three different concentrations of carbon dioxide dissolved in water, in association with a constant concentration of glucose, compared to water alone or added with glucose. In addition, we also tested a sweetened flavoured commercial drink with and without carbon dioxide.

\section{SUBJECTS AND METHODS}

\section{Subjects}

Thirteen healthy volunteers (seven women, six males; median age 22 years; range: 19-24) without current GI symptoms or previous GI illness were recruited. Their mean body mass index (BMI) was $23 \pm 3.5$. Exclusion criteria included: alterations of biochemical analysis; prior abdominal surgery; presence of gallbladder stones; positive symptoms at a dyspeptic or bowel symptoms questionnaire; use of medications known to alter GI function; use of over-the-counter medications for GI symptoms in the 7 days prior to the study. The procedures, purposes and risks of participation were explained, and informed written consent was obtained from the subjects. The study was approved by the Ethics Committee of the 'Federico II' University of Naples. The study was supported by The Beverage Institute for Health \& Wellness (BIHW), L.L.C., Atlanta, GA, USA.

\section{General design}

The study was scheduled to include two arms: study A to test a sweetened beverage with increasing concen- trations of carbon dioxide and study $\mathrm{B}$ to test a sweetened carbonated commercial drink with and without carbon dioxide. Both studies were designed according a double-blind, randomized fashion. Seven subjects (four women, three males; median age 23; mean BMI $22 \pm 4.6)$ participated in study A, and six (three women, three males; median age 20.5; mean BMI $24 \pm 1.2$ ) in study B. Study A subjects were tested for the effect on upper digestive tract of the following five beverages: $A_{1}$, still water; $A_{2}$, still water $+10 \% \mathrm{w} / \mathrm{v}$ sucrose; $A_{3}$, still water $+10 \% \quad w / v \quad$ sucrose + $\left[\mathrm{CO}_{2}\right]=2.0 \mathrm{vol} \% ; \mathrm{A}_{4}$, still water $+10 \% \mathrm{w} / \mathrm{v}$ sucrose $+\left[\mathrm{CO}_{2}\right]=2.8$ vol\%; $\mathrm{A}_{5}$, still water $+10 \% \mathrm{w} / \mathrm{v}$ sucrose $+\left[\mathrm{CO}_{2}\right]=3.75 \mathrm{vol} \%$ (Table 1), all prepared by Coca-Cola Services - R\&D (Brussels, Belgium). Study B subjects were tested for the effect on upper digestive tract of three beverages $\left(B_{1}\right.$, still water; $B_{2}$, decarbonated Sprite ${ }^{\odot} ; B_{3}$, normal Sprite ${ }^{\odot}$. Beverage $B_{1}$ was prepared by Coca-Cola Services. Beverages $B_{2}$ and $B_{3}$ were commercial Sprite ${ }^{\odot}$. Beverage $B_{2}$ was decarbonated by one of the authors $(\mathrm{CC})$, immediately before the experiment, with an ultrasound procedure (Elmasonic S - Ultrasonic Unit, Singen, Germany) and the experiment was performed by two other authors (MFS and GS) blinded to the content of the beverage. All the beverages used in the study were colourless and were put in similar transparent $300 \mathrm{~mL}$ bottles and numbered with a key that was decoded only at the end of each study. The bottles were stored at $4{ }^{\circ} \mathrm{C}$ and administered at $10-12{ }^{\circ} \mathrm{C}$.

After an overnight fast of at least $10 \mathrm{~h}$ all subjects underwent oesophageal $\mathrm{pH}$-impedance, gastric emptying, gallbladder emptying and symptoms questionnaire before and after a meal test, according the following schedule: (i) a first set of experiments to study oesophageal impedance + gastric emptying + symptom questionnaire, which were simultaneously evaluated five

Table 1 Beverage codes

\footnotetext{
Study A

Product $\mathrm{A}_{1}$ : Still water

Product $\mathrm{A}_{2}$ : Still water $+10 \%$ of sucrose; carbonation level: 0.0 vol\%

Product $\mathrm{A}_{3}$ : Still water $+10 \%$ of sucrose; carbonation level: 2.0 vol\%

Product $\mathrm{A}_{4}$ : Still water $+10 \%$ of sucrose; carbonation level: $2.8 \mathrm{vol} \%$

Product $\mathrm{A}_{5}$ : Still water $+10 \%$ of sucrose; carbonation level: $3.75 \mathrm{vol} \%$

Study B

Product $\mathrm{B}_{1}$ : Still water

Product $\mathrm{B}_{2}$ : Sprite ${ }^{\odot}$ without carbon dioxide

Product $\mathrm{B}_{3}$ : Sprite ${ }^{\odot}$ with carbon dioxide
} 
times in study $\mathrm{A}$ and three times in study $\mathrm{B}$, once for each beverage and over a time interval of $5 \mathrm{~h}(1 \mathrm{~h}$ in basal conditions and $4 \mathrm{~h}$ after the meal test) and (ii) a second set of experiments to study gallbladder emptying five times in study A and three times in study B, before and $30 \mathrm{~min}$ after the test meal. Three hundred millilitres of each beverage were administered for each experiment, giving $150 \mathrm{~mL}$ before and $150 \mathrm{~mL}$ after the meal. The subjects were studied over a period of 10 days with a time interval of at least 7 days.

\section{Symptoms score questionnaires}

During gastric emptying and oesophageal impedance studies, each subject completed a symptoms questionnaire in basal conditions and every $15 \mathrm{~min}$ after the meal. This questionnaire assessed belching, satiety, epigastric burning/pain, bloating, heartburn, regurgitation and nausea by a visual analogue score (VAS) of $100 \mathrm{~mm} \cdot{ }^{14,15}$

\section{Oesophageal $\mathrm{pH}$-impedance}

To evaluate gastro-oesophageal reflux activity we performed oesophageal impedance-pH monitoring using a Multi-channel Intraluminal Impedance ambulatory system (Sandhill Scientific, Inc., Highland Ranch, CO, USA). Intraluminal electrical impedance was recorded with a $2.3-\mathrm{mm}$ diameter polyvinyl assembly containing a series of cylindrical electrodes, $4 \mathrm{~mm}$ in axial length each and spaced at $2-\mathrm{cm}$ intervals. ${ }^{16}$ Each pair of electrodes formed a 2-cm long measuring segment, corresponding to one recording channel. Oesophageal $\mathrm{pH}$ was measured with antimony $\mathrm{pH}$ electrodes incorporated in the assembly. The combined assembly included two $\mathrm{pH}$ sensors to be located $5 \mathrm{~cm}$ above and $10 \mathrm{~cm}$ below the LOS, respectively, and impedance segments spanning the distal and mid-oesophageal body. Before the ambulatory study, all subjects underwent a stationary oesophageal manometry to determine the location of the LOS. After the manometry, the combined $\mathrm{pH}$-impedance assembly was passed through the nose and positioned with the proximal (oesophageal) $\mathrm{pH}$ electrode $5 \mathrm{~cm}$ above the LOS, and the distal one (gastric) $10 \mathrm{~cm}$ below the LOS. In this position, the midpoints of the impedance recording segments were located at 3, 5, 7, 9, 15 and $17 \mathrm{~cm}$ proximal to the LOS.

\section{Gastric emptying breath test}

Gastric emptying rates for solids were determined using ${ }^{13} \mathrm{C}$ octanoic acid breath test. ${ }^{12,13}$ The test meal consisted of one scrambled egg, $50 \mathrm{~g}$ ham, $10 \mathrm{~g}$ butter, $60 \mathrm{~g}$ white bread. For the purpose of the breath test, egg yolks were doped with $91 \mathrm{mg}$ of ${ }^{13} \mathrm{C}$ octanoic acid (Eurisotop, Saint-Aubin, France). Total energy intake was $480 \mathrm{kcal}$, and nutrient composition was $26 \mathrm{~g}$ carbohydrates $(32 \%), 16 \mathrm{~g}$ fat $(44 \%)$ and $19 \mathrm{~g}$ protein $(24 \%)$. All meals were consumed within $10 \mathrm{~min}$. Breath samples were taken before the meal and at 15-min intervals for a period of $240 \mathrm{~min}$ postprandially. The ${ }^{13} \mathrm{C}$ content was determined by online gas chromatographic purification-isotope ratio mass spectrometry (ABCA, Europe Scientific, Crewe, UK). Results were expressed as half-time of gastric emptying. The ${ }^{13} \mathrm{CO}_{2}$ excretion curves were analysed according to the formulas of Ghoos et $a .^{17,18}$ and the half emptying times $(t 1 / 2 b)$ and lag phase ( $t$ lag) were calculated.

\section{Gallbladder emptying}

Subjects were evaluated after an overnight fast. Ultrasound images were used to calculate gallbladder basal volume by the ellipsoid method. ${ }^{19}$ Gallbladder diameters can be easily evaluated by real-time ultrasonography by means of two perpendicular scans. The first is made parallel to the main gallbladder axis and corresponds to the longitudinal and anteroposterior diameters. A scan made perpendicular to this plane allows measurement of the transverse diameter. These measurements were used to calculate gallbladder volume before and $30 \mathrm{~min}$ after the ingestion of $250 \mathrm{~mL}$ milk.

\section{Data analysis}

Total, liquid, gas and mixed (gas + liquid) acid and nonacid refluxes were evaluated by oesophageal impedance using a dedicated software and a further visual control for gas refluxes. Gas reflux was defined as a rapid $\left(3 \mathrm{k} \Omega ~ s^{-1}\right)$ increase in impedance $>5000 \Omega$, occurring simultaneously in at least two oesophageal measuring segments, in the absence of swallowing. Mixed liquidgas reflux was defined as gas reflux occurring immediately before or during a liquid reflux. Changes in oesophageal $\mathrm{pH}$ during reflux detected by impedance allowed classification of reflux into: (i) acid reflux, i.e. refluxed gastric juice with a $\mathrm{pH}<4$, which can either reduce the $\mathrm{pH}$ of the oesophagus to below 4 or occur when oesophageal $\mathrm{pH}$ is already below 4 and (ii) nonacidic refluxes, which encompass weakly acidic refluxes considered to result in an oesophageal $\mathrm{pH}$ between 4 and 7, and alkaline reflux defined as reflux episodes during which oesophageal $\mathrm{pH}$ does not drop below $7 .^{20}$ Heartburn and acid regurgitation were considered in the analysis of symptoms. The analysis was performed 
using five time fractions: basal hour, and first, second, third and fourth hour after the meal test.

Upper GI symptoms were evaluated by VAS, and the results were expressed in millimetre as the sum of each measure collected every $15 \mathrm{~min}$ after consuming the test meal and beverage.

To study gastric emptying we evaluated half emptying time and lag phase. Gallbladder contraction was measured evaluating per cent of contraction after meal.

A preliminary evaluation of data variability was performed to calculate sample size and statistical power. Total refluxes were measured in five healthy subjects by oesophageal impedance, twice for $2 \mathrm{~h}$ after a standard meal associated with carbonated water. Data from these experiments were used to calculate samples size and the related statistical power. We calculated mean difference and SD of differences between the two series of experiments. Based on these data, and assuming alpha as 0.05 , we extrapolated the following statistical power for each sample size: 0.73 for five cases; 0.85 for six; 0.92 for seven and 0.96 for eight.
Statistical analyses were performed by one-way analysis of variance and Dunnet multiple comparison post-test considering beverages $\mathrm{A}_{1}$ and $\mathrm{B}_{1}$ (water) as controls; the Tukey Kramer post-test was utilized to compare all pairs of samples. Data were expressed as mean \pm SD. Statistical significance was set at $P<0.05$.

\section{RESULTS}

\section{Symptoms}

Study $A$ The analysis of symptoms collected during the gastric emptying and oesophageal impedance studies showed the absence of regurgitation, heartburn and epigastric burning in all experiments. Only one subject referred nausea with the same severity in all five tests. All subjects experienced satiety during the experiments and only three referred a moderate sensation of similar intensity during all tests, although no differences were observed correlated to the intake of five drinks (see Fig. 1A). Belching was markedly present in
Figure 1 (A) Analysis of postprandial sensations collected in study $A$ with the five beverages $\left(\mathrm{A}_{1}\right.$ : still water; $\mathrm{A}_{2}$ : still water $+10 \%$ of sucrose; carbonation level: 0.0 vol\%; $\mathrm{A}_{3}$ : still water $+10 \%$ of sucrose; carbonation level: $2.0 \mathrm{vol} \% ; \mathrm{A}_{4}$ : still water $+10 \%$ of sucrose; carbonation level: 2.8 vol\%; $\mathrm{A}_{5}$ : still water $+10 \%$ of sucrose; carbonation level: $3.75 \mathrm{vol} \%$ ). The figure shows the intensity by visual analogue scale (VAS) expressed as millimetre of symptoms referred (belching, bloating and satiety). Dash line is the mean. $P=$ all ns. (B) Analysis of postprandial sensations collected in study $\mathrm{B}$ with the three beverages $\left(\mathrm{B}_{1}\right.$ : still water; $\mathrm{B}_{2}$ : Sprite $^{\odot}$ without carbon dioxide; $\mathrm{B}_{3}$ : Sprite $^{\odot}$ with carbon dioxide). The figure shows the intensity by VAS expressed as millimetre of symptoms referred (belching, bloating and satiety). The dash line represents the mean. $P=$ all ns.
A
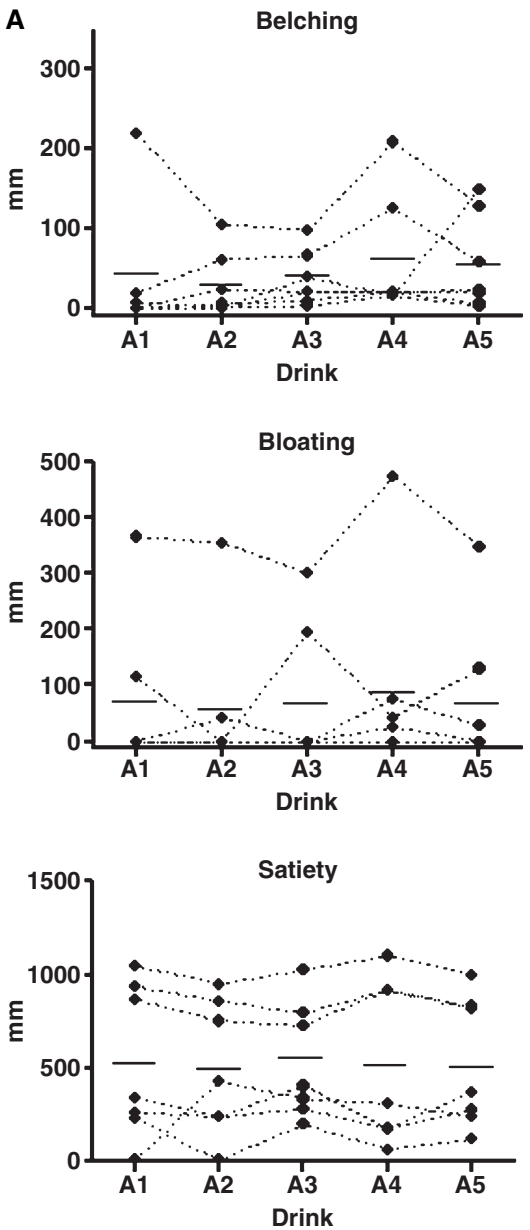
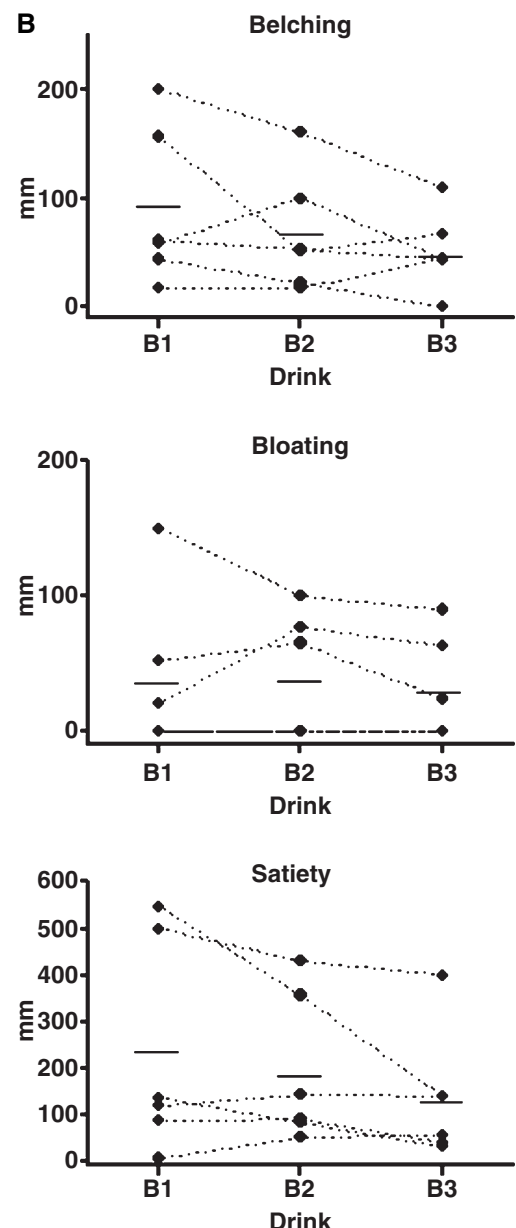
two subjects, while in a third it increased with the intake of beverage $A_{5}$, which had the greatest $\mathrm{CO}_{2}$ content (Fig. 1A). Globally, belching appeared to have a trend to increase - albeit not significantly - in parallel with $\mathrm{CO}_{2}$ content. Bloating was also clearly observed in two subjects. However, no significant differences were found for either belching or bloating in the five tests using the different beverages.

Study B In this study, none of the subjects experienced nausea, regurgitation, heartburn or epigastric burning in any of the experiments. Belching was relevant in two subjects when they drank still water $\left(B_{1}\right)$ but it decreased when they drank decarbonated and carbonated drinks; mean variation among different beverages was not significant (Fig. 1B). Bloating was slightly marked in one patient and satiety was relevant in two patients but it decreased in one after drinking $\mathrm{B}_{2}$ and $\mathrm{B}_{3}$ beverages; therefore there were no differences between experiments with the three beverages for both symptoms.

\section{Oesophageal impedance}

Study A The number of total gastro-oesophageal refluxes was similar in basal condition for all experiments before the intake of the different beverages and the meal (Fig. 2A). One hour after the meal, total refluxes increased significantly compared to basal values in all the experiments, showing similar effects
A

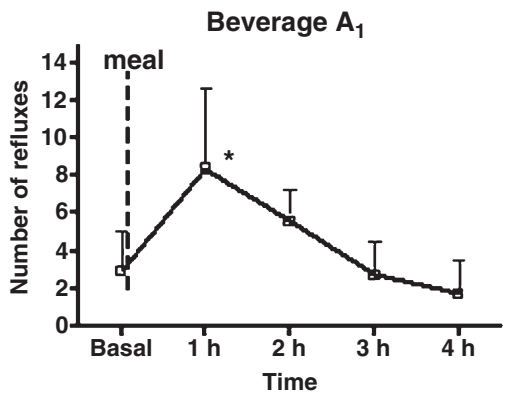

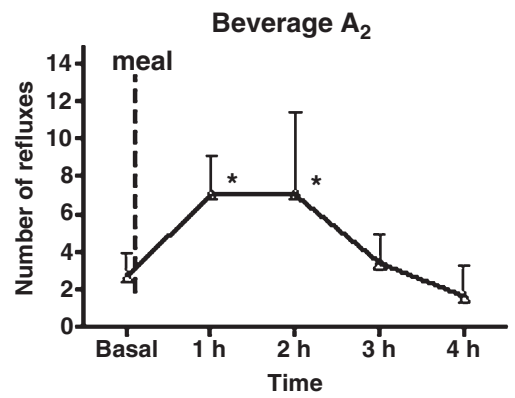

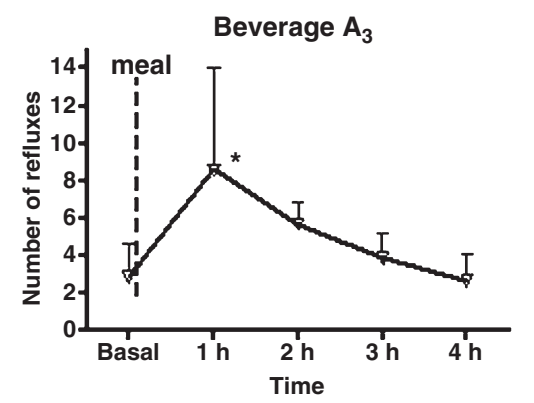

B

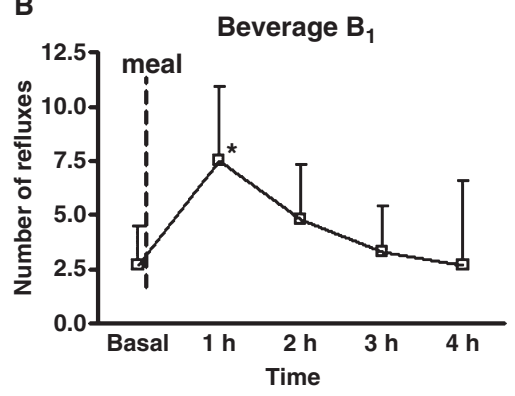

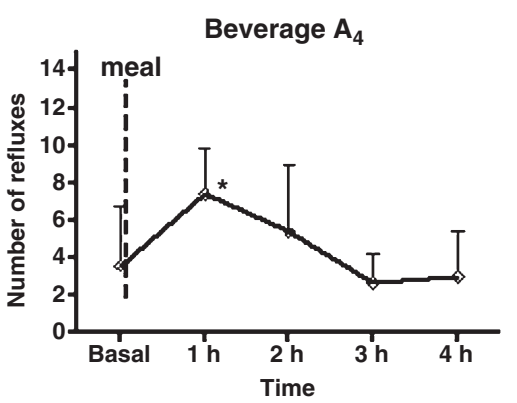

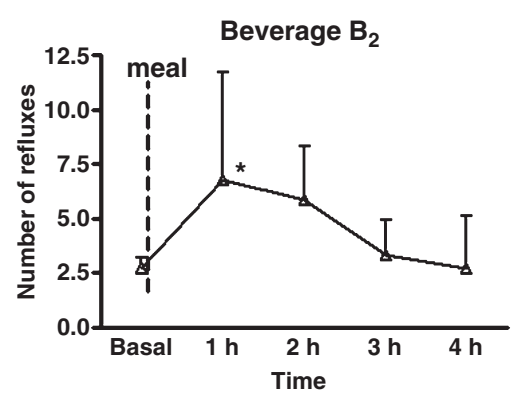

Beverage $\mathbf{A}_{5}$
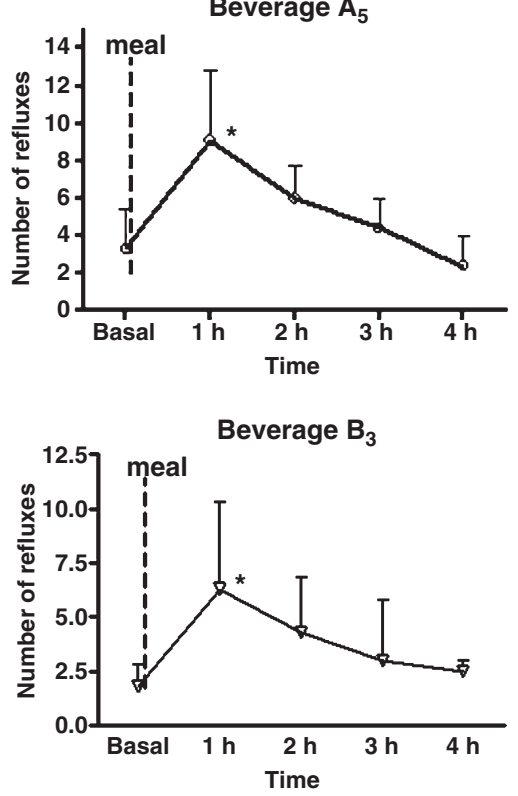

Figure 2 (A) Number of total gastroesophageal refluxes recorded by $\mathrm{pH}$-impedance $1 \mathrm{~h}$ before and $4 \mathrm{~h}$ after meal and the five beverages in study $\mathrm{A}\left(\mathrm{A}_{1}\right.$ : still water; $\mathrm{A}_{2}$ : still water $+10 \%$ of sucrose; carbonation level: 0.0 vol $\% ; \mathrm{A}_{3}$ : still water $+10 \%$ of sucrose; carbonation level: 2.0 vol $\%$; $\mathrm{A}_{4}$ : still water $+10 \%$ of sucrose; carbonation level: $2.8 \mathrm{vol} \%$; $\mathrm{A}_{5}$ : still water $+10 \%$ of sucrose; carbonation level: $3.75 \mathrm{vol} \%)$. ${ }^{\star} P<0.05 \mathrm{vs}$ basal level. (B) Number of total gastroesophageal refluxes recorded by $\mathrm{pH}$-impedance $1 \mathrm{~h}$ before and $4 \mathrm{~h}$ after meal and the three beverages in study $\mathrm{B}\left(\mathrm{B}_{1}\right.$ : still water; $\mathrm{B}_{2}$ : Sprite ${ }^{\odot}$ without carbon dioxide; $\mathrm{B}_{3}$ : Sprite ${ }^{\odot}$ with carbon dioxide). ${ }^{\star} P<0.05$ vs basal level. 
with the different beverages. However, this increase remained significant $2 \mathrm{~h}$ postmeal only with beverage $\mathrm{A}_{2}$, showing persisting postprandial refluxes with sugared water without carbon dioxide.

The analysis of different kinds of refluxes showed that liquid and acid refluxes were significantly increased $1 \mathrm{~h}$ postmeal compared to the value before the meal, and only acid refluxes remained significantly higher at the second hour (Table 2). In addition, a significant increase in non-acid refluxes was also found when subjects drank still water. There was a nonsignificant increase in pure gas refluxes at $1 \mathrm{~h}$ postmeal and thereafter in all the experiments with different beverages. Moreover, mixed refluxes, i.e. the simultaneous occurrence of liquid and gas refluxes, were not significantly increased.

Study $B$ In this study, where we verified the effect of a flavoured drink, we confirmed that total refluxes increased significantly $1 \mathrm{~h}$ postmeal with all the three beverages tested (Fig. 2B). A mild, but non-significant trend to plateau was found $2 \mathrm{~h}$ after the meal only with decarbonated flavoured drink $\left(\mathrm{B}_{2}\right)$, showing a trend similar to the effect due to beverage $\mathrm{A}_{2}$.

The analysis of the different kinds of refluxes also showed that liquid and acid refluxes were significantly increased $1 \mathrm{~h}$ postmeal compared to premeal values (Table 3). An additional time analysis showed the persistence of a significant increase in acid refluxes at $2 \mathrm{~h}$ with all drinks but beverage $\mathrm{B}_{3}$. Moreover, non-acid refluxes showed an increase - albeit non-significant when subjects drank still water. Gas refluxes were not increased $1 \mathrm{~h}$ postmeal or subsequently in any of the experiments using the different beverages. Mixed refluxes appeared slightly but significantly increased $1 \mathrm{~h}$ postmeal, compared to preprandial values, only in subjects who drank still water.

\section{Gastric emptying breath test}

Study A Sweetened $\left(\mathrm{A}_{2}\right)$ or sweetened carbonated $\left(\mathrm{A}_{3}\right.$, $A_{4}$ and $A_{5}$ ) beverages did not significantly influence the
Table 2 Esophageal pH-impedance in seven subjects of study A

\begin{tabular}{|c|c|c|c|c|c|}
\hline Drink & Basal & $1 \mathrm{~h} \mathrm{PP}$ & $2 \mathrm{~h} \mathrm{PP}$ & $3 \mathrm{~h} \mathrm{PP}$ & $4 \mathrm{~h} \mathrm{PP}$ \\
\hline \multicolumn{6}{|c|}{ Liquid refluxes } \\
\hline $\mathrm{A}_{1}$ & $1.00 \pm 1.50$ & $3.20 \pm 2.20$ & $1.85 \pm 1.50$ & $0.71 \pm 1.20$ & $0.57 \pm 1.13$ \\
\hline$A_{2}$ & $0.43 \pm 1.13$ & $3.71 \pm 1.40^{\star}$ & $3.80 \pm 4.25^{\star}$ & $1.28 \pm 1.13$ & $0.28 \pm 0.76$ \\
\hline $\mathrm{A}_{3}$ & $0.57 \pm 0.70$ & $4.50 \pm 4.50^{\star}$ & $2.40 \pm 1.80$ & $0.80 \pm 0.90$ & $0.70 \pm 1.11$ \\
\hline $\mathrm{A}_{4}$ & $0.85 \pm 1.21$ & $3.28 \pm 2.05^{\star}$ & $2.50 \pm 2.20$ & $0.85 \pm 1.21$ & $1.28 \pm 1.70$ \\
\hline $\mathrm{A}_{5}$ & $0.85 \pm 1.46$ & $4.14 \pm 2.26^{\star}$ & $2.70 \pm 2.00$ & $1.71 \pm 0.95$ & $0.42 \pm 0.70$ \\
\hline \multicolumn{6}{|c|}{ Mixed refluxes } \\
\hline $\mathrm{A}_{1}$ & $1.39 \pm 1.60$ & $4.42 \pm 3.10$ & $3.40 \pm 1.70$ & $1.57 \pm 1.39$ & $0.71 \pm 0.95$ \\
\hline $\mathrm{A}_{2}$ & $1.85 \pm 1.46$ & $3.28 \pm 2.21$ & $3.20 \pm 1.97$ & $2.14 \pm 1.34$ & $0.85 \pm 1.86$ \\
\hline$A_{3}$ & $1.57 \pm 1.13$ & $3.14 \pm 2.67$ & $3.28 \pm 1.70$ & $2.57 \pm 1.90$ & $1.57 \pm 1.13$ \\
\hline $\mathrm{A}_{4}$ & $1.28 \pm 1.60$ & $2.86 \pm 1.35$ & $2.57 \pm 2.07$ & $1.14 \pm 0.89$ & $1.28 \pm 1.70$ \\
\hline $\mathrm{A}_{5}$ & $2.00 \pm 1.29$ & $4.70 \pm 3.40$ & $2.70 \pm 2.20$ & $2.57 \pm 1.51$ & $1.71 \pm 1.79$ \\
\hline \multicolumn{6}{|c|}{ Gas refluxes } \\
\hline $\mathrm{A}_{1}$ & $0.71 \pm 0.76$ & $0.71 \pm 0.49$ & $0.14 \pm 0.38$ & $0.43 \pm 0.53$ & $0.71 \pm 0.76$ \\
\hline $\mathrm{A}_{2}$ & $0.43 \pm 0.53$ & $0.14 \pm 0.38$ & $0.00 \pm 0.00$ & $0.00 \pm 0.00$ & $0.43 \pm 0.53$ \\
\hline $\mathrm{A}_{3}$ & $0.86 \pm 1.21$ & $0.86 \pm 1.21$ & $0.00 \pm 0.00$ & $0.29 \pm 0.49$ & $0.57 \pm 0.79$ \\
\hline $\mathrm{A}_{4}$ & $1.14 \pm 0.90$ & $1.71 \pm 1.25$ & $0.57 \pm 0.79$ & $0.71 \pm 0.95$ & $0.43 \pm 0.79$ \\
\hline $\mathrm{A}_{5}$ & $0.43 \pm 0.79$ & $0.29 \pm 0.49$ & $0.57 \pm 1.13$ & $0.29 \pm 0.49$ & $0.29 \pm 0.49$ \\
\hline \multicolumn{6}{|c|}{ Acid refluxes } \\
\hline $\mathrm{A}_{1}$ & $1.57 \pm 1.90$ & $4.57 \pm 2.99^{\star}$ & $5.20 \pm 1.88^{\star}$ & $1.85 \pm 1.34$ & $1.00 \pm 1.52$ \\
\hline$A_{2}$ & $1.71 \pm 1.38$ & $5.42 \pm 3.04^{\star}$ & $5.71 \pm 4.23^{\star}$ & $2.28 \pm 1.49$ & $1.00 \pm 1.15$ \\
\hline $\mathrm{A}_{3}$ & $1.00 \pm 1.41$ & $5.85 \pm 3.18^{\star}$ & $4.57 \pm 0.97^{\star}$ & $3.14 \pm 1.57$ & $1.71 \pm 1.70$ \\
\hline $\mathrm{A}_{4}$ & $1.57 \pm 1.90$ & $4.28 \pm 1.60^{\star}$ & $4.00 \pm 2.40$ & $1.40 \pm 1.27$ & $1.42 \pm 2.00$ \\
\hline $\mathrm{A}_{5}$ & $1.71 \pm 1.70$ & $7.28 \pm 3.14^{\star}$ & $4.71 \pm 1.97^{\star}$ & $3.14 \pm 1.57$ & $1.71 \pm 1.25$ \\
\hline \multicolumn{6}{|c|}{ Non-acid refluxes } \\
\hline $\mathrm{A}_{1}$ & $0.20 \pm 0.75$ & $3.85 \pm 1.95^{\star}$ & $0.28 \pm 0.4$ & $0.85 \pm 0.69$ & $0.71 \pm 0.75$ \\
\hline$A_{2}$ & $0.71 \pm 0.75$ & $1.71 \pm 1.38$ & $1.43 \pm 2.07$ & $1.14 \pm 0.37$ & $0.57 \pm 0.78$ \\
\hline $\mathrm{A}_{3}$ & $0.42 \pm 0.53$ & $2.71 \pm 4.23$ & $1.00 \pm 0.81$ & $0.71 \pm 0.95$ & $1.00 \pm 1.00$ \\
\hline $\mathrm{A}_{4}$ & $1.00 \pm 1.15$ & $3.00 \pm 1.60$ & $1.43 \pm 1.51$ & $1.28 \pm 1.11$ & $1.57 \pm 1.71$ \\
\hline $\mathrm{A}_{5}$ & $0.85 \pm 0.69$ & $1.86 \pm 2.48$ & $1.28 \pm 1.11$ & $1.28 \pm 1.11$ & $0.71 \pm 0.75$ \\
\hline
\end{tabular}

Number of acid, non-acid, liquid, mixed and gas refluxes calculated before and after a test meal. PP, post prandial.

${ }^{\star} P<0.05$ vs basal value. 


\begin{tabular}{|c|c|c|c|c|c|}
\hline Drink & Basal & $1 \mathrm{~h} \mathrm{PP}$ & $2 \mathrm{~h} \mathrm{PP}$ & 3 h PP & $4 \mathrm{~h} \mathrm{PP}$ \\
\hline \multicolumn{6}{|c|}{ Liquid refluxes } \\
\hline $\mathrm{B}_{1}$ & $0.83 \pm 0.98$ & $4.67 \pm 3.82^{\star}$ & $2.17 \pm 1.32$ & $1.00 \pm 1.26$ & $1.50 \pm 2.81$ \\
\hline $\mathrm{B}_{2}$ & $0.67 \pm 0.51$ & $3.20 \pm 2.30^{\star}$ & $2.67 \pm 2.40$ & $1.00 \pm 1.54$ & $0.33 \pm 0.51$ \\
\hline $\mathrm{B}_{3}$ & $0.33 \pm 0.81$ & $2.33 \pm 1.63^{\star}$ & $1.67 \pm 1.50$ & $0.83 \pm 1.60$ & $0.50 \pm 0.83$ \\
\hline \multicolumn{6}{|c|}{ Mixed refluxes } \\
\hline $\mathrm{B}_{1}$ & $0.50 \pm 0.40$ & $2.50 \pm 1.87^{\star}$ & $1.50 \pm 1.64$ & $1 \pm 1.26$ & $0.33 \pm 0.52$ \\
\hline $\mathrm{B}_{2}$ & $1.17 \pm 1.16$ & $3.33 \pm 4.37$ & $2.67 \pm 2.50$ & $2 \pm 1.55$ & $1.67 \pm 1.03$ \\
\hline $\mathrm{B}_{3}$ & $0.33 \pm 0.52$ & $2.83 \pm 3.10$ & $2.50 \pm 2.43$ & $1.67 \pm 1.86$ & $1.67 \pm 0.82$ \\
\hline \multicolumn{6}{|c|}{ Gas refluxes } \\
\hline $\mathrm{B}_{1}$ & $1.33 \pm 1.03$ & $0.17 \pm 0.41$ & $1.17 \pm 1.47$ & $1.33 \pm 1.51$ & $0.83 \pm 0.75$ \\
\hline $\mathrm{B}_{2}$ & $0.83 \pm 0.98$ & $0.67 \pm 1.21$ & $0.17 \pm 0.41$ & $0.33 \pm 0.82$ & $0.67 \pm 1.21$ \\
\hline $\mathrm{B}_{3}$ & $0.67 \pm 1.03$ & $1.17 \pm 1.47$ & $0.17 \pm 0.41$ & $0.50 \pm 0.84$ & $0.33 \pm 0.52$ \\
\hline \multicolumn{6}{|c|}{ Acid refluxes } \\
\hline $\mathrm{B}_{1}$ & $0.33 \pm 0.82$ & $3.67 \pm 2.94^{\star}$ & $3.33 \pm 1.72^{\star}$ & $1.17 \pm 1.16$ & $0.83 \pm 1.33$ \\
\hline $\mathrm{B}_{2}$ & $1.17 \pm 0.75$ & $4.50 \pm 4.46^{\star}$ & $4.50 \pm 2.88^{\star}$ & $2.50 \pm 1.51$ & $1.17 \pm 1.16$ \\
\hline $\mathrm{B}_{3}$ & $0.50 \pm 0.83$ & $3.83 \pm 2.06^{\star}$ & $3.60 \pm 3.57$ & $1.67 \pm 1.96$ & $1.00 \pm 0.63$ \\
\hline \multicolumn{6}{|c|}{ Non-acid refluxes } \\
\hline $\mathrm{B}_{1}$ & $1.37 \pm 1.60$ & $3.83 \pm 3.43$ & $1.67 \pm 1.60$ & $2.00 \pm 1.26$ & $2.00 \pm 3.46$ \\
\hline $\mathrm{B}_{2}$ & $1.30 \pm 1.26$ & $2.33 \pm 1.63$ & $1.33 \pm 1.21$ & $0.83 \pm 1.32$ & $1.50 \pm 1.76$ \\
\hline $\mathrm{B}_{3}$ & $0.67 \pm 1.03$ & $2.70 \pm 2.50$ & $0.33 \pm 0.81$ & $1.33 \pm 1.21$ & $1.50 \pm 0.54$ \\
\hline
\end{tabular}

Table 3 Esophageal $\mathrm{pH}$-impedance in six subjects of study B

Number of acid, non-acid, liquid, mixed and gas refluxes calculated before and after a test meal. PP, post prandial.

${ }^{\star} P<0.05$ vs basal.

gastric emptying of a standardized meal compared to the intake of the same amount of a still water beverage $\left(\mathrm{A}_{1}\right)$. A slight but non-significant reduction in gastric emptying time of the test meal was observed when it was associated with the intake of still water (Fig. 3A). The intraindividual analysis did not show any significant variation trend. Gastric lag phases were not different between the five beverages .

Study B Carbonated and non-carbonated flavoured drinks did not seem to influence gastric emptying. However, a slight but non-significant decrease in gastric emptying time was recorded with beverage $B_{3}$ (carbonated flavoured drink); specifically, compared to $\mathrm{B}_{2}$ (non-carbonated flavoured drink) the value decreased in four of six subjects, whereas it increased in two. Gastric lag phase were not different among the three beverages.

\section{Gallbladder emptying}

Study $A$ The increased carbon dioxide concentration in sweetened beverages did not affect gallbladder contraction either before or after a milk meal, as measured by the ultrasound method. A more careful analysis showed a slight but non-significant gallbladder contraction at 30 min after the meal when subjects drank still water. Therefore, the intraindividual analysis also showed that different beverages did not determine a significant variation in gallbladder emptying after sweetened or sweetened carbonated beverages compared to still water (Fig. 3A).

Study B Carbonated and non-carbonated flavoured drinks did not seem to influence gallbladder emptying compared to still water. Here again, the intraindividual analysis failed to find any significant variation between beverages (Fig. 3B).

\section{DISCUSSION}

These studies have been performed on healthy subjects to verify the effect, on the upper digestive tract, of sweetened (sucrose 10\%) water added with increased concentrations of carbon dioxide, and of a commercial carbonated and non-carbonated flavoured drink $\left(\right.$ Sprite $\left.^{\odot}\right)$. The analysis of the data show that sweetened carbonated water and flavoured drinks, independently of carbonation level, compared to still water, do not significantly alter the physiology of the upper digestive tract. Therefore, some results of these studies must be underlined.

During the experiments the subjects did not report symptoms such as heartburn, nausea, epigastric burning or epigastric pain. Moderate belching and bloating were reported in both studies and their intensity did not correlate with the presence of, or increase in, carbon dioxide concentrations. Satiety is the only 
Figure 3 (A) Half gastric emptying time (top) and per cent of gallbladder contraction (bottom) during the experiments with five beverages in study $\mathrm{A}$ $\left(\mathrm{A}_{1}\right.$ : still water; $\mathrm{A}_{2}$ : still water $+10 \%$ of sucrose; carbonation level: $0.0 \mathrm{vol} \%$; $\mathrm{A}_{3}$ : still water $+10 \%$ of sucrose; carbonation level: 2.0 vol\%; $\mathrm{A}_{4}$ : still water $+10 \%$ of sucrose; carbonation level: 2.8 vol $\%$; $\mathrm{A}_{5}$ : still water $+10 \%$ of sucrose; carbonation level: $3.75 \mathrm{vol} \%)$. Dash line is the mean. $P=$ all ns. (B) Half gastric emptying time (top) and per cent of gallbladder contraction (bottom) during the experiments with three beverages in study A ( $B_{1}$ : still water; $B_{2}$ : Sprite ${ }^{\odot}$ without carbon dioxide; $\mathrm{B}_{3}:$ Sprite $^{\mathscr{\odot}}$ with carbon dioxide). The dash line represents the mean. $P=$ all ns.
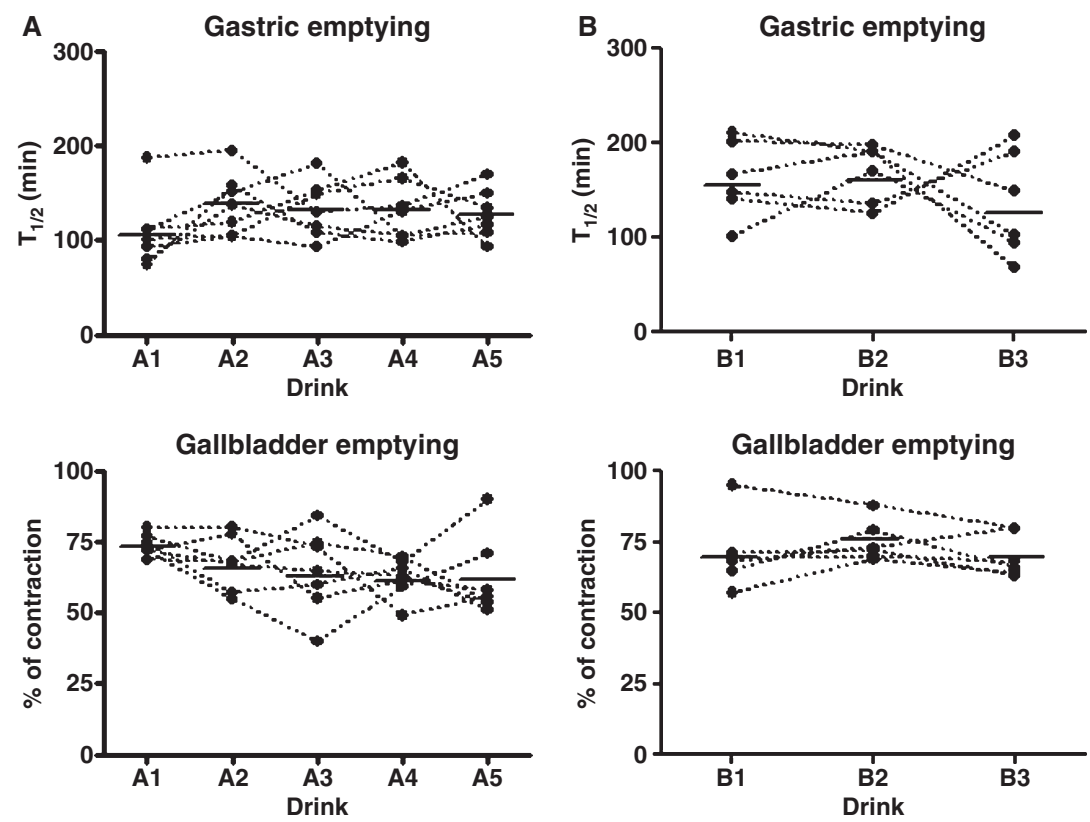

sensation that appeared marked in some subjects during the experiments based on beverages with increased carbonation and with commercial flavoured drinks with or without carbon dioxide. The evaluation of satiety referred by subjects participating in each study showed an equal intensity in all the experiments. Specifically, in subjects in whom the feeling was relevant with natural water, it was the same also with sweetened beverages with or without carbon dioxide.

The absence of triggering symptoms in healthy subjects during the ingestion of carbonated beverages was basically confirmed also in other studies. Zachweieja et al. performed two different experiments during an exercise performance test, showing that carbonated and non-carbonated water - independently of the sugar content - did not determine perception of GI discomfort. ${ }^{1}$ Only few subjects in these experiments reported symptoms of GI distress while drinking a carbonated beverage, but some also reported similar symptoms when ingesting a non-carbonated beverage. At variance with our studies, the most common complaints in these subjects were nausea and heartburn. Pouderaux et al., also found no difference in the feeling of fullness between carbonated and still water added to a meal of 700 calories, but showed an increased need to belch after carbonated water. ${ }^{12}$ Three studies performed during physical exercise showed that carbonated and non-carbonated water, whether sweetened or not, determined low GI distress, ${ }^{21-23}$ and the prevalent symptoms described were fullness and heartburn. In most of these studies the intake of beverages was ad libitum with an average quantity of $1000 \mathrm{~mL}$. In another study, where the amount of beverage $360 \mathrm{~mL}$, assumed to be a commonly consumed portion - was similar to that administered in our study, the authors failed to find differences in the sensations of fullness when the subjects drank either water, diet cola or regular cola. ${ }^{24}$

Contrasting results come from two other studies. In the first one, performed with magnetic resonance imaging, the authors showed that after the intake of $800 \mathrm{~mL}$ of either water, sweetened non-carbonated, lightly carbonated solution or regular cola, without a meal, there was an increase in gastric distress and delay gastric emptying only after drinking regular cola. ${ }^{25}$ The second study was aimed to verify energy intake after a $590 \mathrm{~mL}$ preload beverage using regular cola or sparkling water; regular cola determined an initial increase in satiety without reducing energy intake $175 \mathrm{~min}$ after drinking the beverage. ${ }^{26}$ The differences between those findings and ours can be explained by the different method utilized.

Intriguing are also the findings of the study of gastrooesophageal reflux evaluated with $\mathrm{pH}$-impedance, a method that allows detection of different kinds of refluxes - i.e. liquid, gaseous, mixed, acid and nonacid. $^{20}$ Total refluxes were significantly increased $1 \mathrm{~h}$ after the meal with both water and commercial beverages; only sweetened water without carbon dioxide (study arm A) determined a persistently increased number of refluxes $2 \mathrm{~h}$ after a meal. A similar but not significant result was found using a commercial 
beverage without carbon dioxide (study arm B). To explain this result we hypothesized that the slight but not significant delay in gastric emptying with sweetened beverages increased the probability of experiencing a gastro-oesophageal reflux. Moreover, in the other sweetened beverages, the presence of carbon dioxide, which could represent a layer of separation between solid/liquid content and gastro-oesophageal junction, could reduce this probability in healthy subjects.

Therefore, our data show that different levels of carbon dioxide did not affect gastro-oesophageal reflux activity in healthy subjects. However, the characterization of the type of refluxes did not show any differences in the mixed type, i.e. liquid and gaseous oesophageal refluxes. Peculiarly, gas refluxes did not increase in healthy subjects consuming the experimental beverages tested in our study, even with the greatest carbonation.

Previous studies performed with sweetened carbonated beverages have often reported heartburn as the prevalent ensuing symptom - but they employed large amounts of beverages; moreover, this symptom was found also using non-carbonated beverages. ${ }^{1,21}$ In one of these studies, where the volume of drink ingested was about $1000 \mathrm{~mL}$, the sensation of needing to belch was frequently experienced by all the subjects consuming a carbonated beverage, while only half reported the same sensation with a non-carbonated drink. ${ }^{1}$ Our studies confirm the presence of belching, mainly an expression of gas reflux, without evidence of an increase in this symptom due to beverage carbonation.

The study of gastric emptying with the five beverages and the commercial drinks did not show significant differences in the various experiments. Hence, sweetened beverages or sweetened beverages added with carbon dioxide did not influence the gastric emptying of a standard meal of $480 \mathrm{kcal}$. However, a careful observation of the data shows that, when the drink is natural water $\left(A_{1}\right)$, the emptying time for the stomach is shorter compared to other conditions; this finding, however, failed to reach statistical significance. The trend to a light but non-significant increase in gastric emptying time after a meal consumed with a sweetened beverage can be correlated with the presence of an increased calorie intake $(+120 \mathrm{kcal})$ because of the $30 \mathrm{~g}$ sucrose contained in these drinks. On the other hand, in study arm B, where the beverages tested were Sprite $^{\odot}$ and decarbonated Sprite ${ }^{\odot}$, we found a slight but non-significant decrease in gastric emptying time with the carbonated drink compared with the decarbonated drink or still water. However, our results excluded a convincing effect of beverage carbonation on gastric emptying, and confirmed the results of some previous studies. ${ }^{12,25}$

An observation very similar to the one regarding gastric emptying has been made during the gallbladder contraction test. As a matter of fact, in study A, there was no significant difference in the percentage of gallbladder contraction after a milk meal administered with natural water, sucrose and sucrose plus carbon dioxide, at three different concentrations. Each subject had a similar gallbladder emptying time during each of the five experiments. Therefore, a slight but not statistically significant trend to a more marked gallbladder contraction was observed when still water was administered together with the milk meal, compared to the condition in which sweetened water with and without carbon dioxide was administered. This trend to a less marked contraction with sweetened beverages can be correlated, also in this case, with the presence of an increased calorie content of the test meal and to the consequent delayed gastric emptying time.

Differently from gastric emptying, gallbladder contraction did not seem to differ in the experiments of study B, which was performed using Sprite ${ }^{\odot}$, decarbonated Sprite ${ }^{\odot}$ and still water, and showed a clear lack of effects of the soft drink on gallbladder motility.

In conclusion, this study shows that $300 \mathrm{~mL}$ of sweetened carbonated beverage with different levels of carbonation and a commercial soft drink containing sugar, carbon dioxide, sodium and an artificial flavouring do not modify the physiology of the upper digestive tract in healthy subjects. This conclusion is supported by both the presence of GI sensation of similar intensity as that occurring when still water is consumed, and the fact that gastro-oesophageal reflux activity, gastric and gallbladder emptying are not modified by the administration of these beverages.

\section{ACKNOWLEDGMENTS}

This study has been supported by The Beverage Institute for Health \& Wellness (BIHW), L.L.C., Atlanta, USA. The authors thank Rosanna Scala for helping with the preparation of the manuscript.

\section{REFERENCES}

1 Zachwieja JJ, Costill DL, Beard GC et al. The effects of a carbonated carbohydrate drink on gastric emptying, gastrointestinal distress, and exercise performance. Int I Sport Nutr 1992; 2: 239-50.

2 Mayne ST, Risch HA, Dubrow R et al. Carbonated soft drink consumption and risk of esophageal adenocarcinoma. J Natl Cancer Inst 2006; 1: 72-5. 
3 Fass R, Quan SF, O'Connor GT, Ervin A, Iber C. Predictors of heartburn during sleep in a large prospective cohort study. Chest 2005; 127: 1658-66.

4 Jensdottir T, Arnadottir IB, Thorsdottir I et al. Relationship between dental erosion, soft drink consumption, and gastroesophageal reflux among Icelanders. Clin Oral Investig 2004; 8: 91-6.

5 Shoenut JP, Duerksen D, Yaffe CS. Impact of ingested liquids on 24-hour ambulatory $\mathrm{pH}$ tests. Dig Dis Sci 1998; 43: 834-9.

6 Stubbs J, Whybrow S. Beverages, appetite, and energy balance. In: Wilson T, Temple NJ, eds. Beverages in Nutrition and Health. Totowa, NJ: Humana Press, 2003: 261-78.

7 Straathof JW, Ringers J, Lamers CB, Masclee AA. Provocation of transient lower esophageal sphincter relaxations by gastric distension with air. Am I Gastroenterol 2001; 96: $2317-23$.

8 Hamoui N, Lord RV, Hagen JA, Theisen J, Demeester TR, Crookes PF. Response of the lower esophageal sphincter to gastric distention by carbonated beverages. J Gastrointest Surg 2006; 10: 870-7.

9 Agrawal A, Tutuian R, Hila A, Freeman J, Castell DO. Ingestion of acidic foods mimics gastroesophageal reflux during pH monitoring. Dig Dis Sci 2005; 50: 1916-20.

10 Cuomo R, Grasso R, Sarnelli G et al. Effects of carbonated water on functional dyspepsia and constipation. Eur $J$ Gastroenterol Hepatol 2002; 14: 991-9.

11 Greenberg LA, Turner JM. Effect of carbonated water on gastric acid secretion. NEJM 1955; 253: 105-7.

12 Pouderoux P, Friedman N, Shirazi P et al. Effect of carbonated water on gastric emptying and intragastric meal distribution. Dig Dis Sci 1997; 42: 34-9.

13 Zachwieja JJ, Costill DL, Widrick JJ, Anderson DE, McConell GK. Effects of drink carbonation on the gastric emptying characteristics of water and flavoured water. Int J Sport Nutr 1991; 1: 45-51.

14 Parker BA, Sturm K, MacIntosh CG, Feinle C, Horowitz M, Chapman IM. Relation between food intake and visual analogue scale ratings of appetite and other sensations in healthy older and young subjects. Eur J Clin Nutr 2004; 58: 212-8.

15 Cuomo R, Sarnelli G, Grasso R et al. Functional dyspepsia symptoms, gastric emptying and satiety provocative test: analysis of relationships. Scand J Gastroenterol 2001; 36: 1030-6.

16 Sifrim D, Silny J, Holloway RH, Janssens JJ. Patterns of gas and liquid reflux during transient lower oesophageal sphincter relaxation: a study using intraluminal electrical impedance. Gut 1999; 44: 47-54.

17 Ghoos YF, Maes BD, Geypens BJ et al. Measurement of gastric emptying rate of solids by means of a carbon-labeled octanoic acid breath test. Gastroenterology 1993; 104: 1640-7.

18 Sarnelli G, Caenepeel P, Geypens B, Janssens J, Tack J. Symptoms associated with impaired gastric emptying of solids and liquids in functional dyspepsia. Am I Gastroenterol 2003; 98: 783-8.

19 Stolk MFJ, Van Erpecum KJ, Van Berge Henegouwen GP et al. Gallbaldder volume and contraction measured by sum-of-cylinders method compared with ellipsoid and area length methods. Acta Radiol 1990; 31: 591-6.

20 Sifrim D, Castell D, Dent J, Kahrilas PJ. Gastro-oesophageal reflux monitoring: review and consensus report on detection and definitions of acid, non-acid, and gas reflux. Gut 2004; 53: 1024-31.

21 Hickey MS, Costill DL, Trappe SW. Drinking behavior and exercise-thermal stress: role of drink carbonation. Int $J$ Sport Nutr 1994; 4: 8-21.

22 Lambert GP, Bleiler TL, Chang RT, Johnson AK, Gisolfi $\mathrm{CV}$. Effects of carbonated and noncarbonated beverages at specific intervals during treadmill running in the heat. Int I Sport Nutr 1993; 3: 177-93.

23 Ryan AJ, Navarre AE, Gisolfi CV. Consumption of carbonated and noncarbonated sports drinks during prolonged treadmill exercise in the heat. Int I Sport Nutr 1991; 1: 225-39.

24 DellaValle DM, Roe LS, Rolls BJ. Does the consumption of caloric and non-caloric beverages with a meal affect energy intake? Appetite 2005; 44: 187-93.

25 Ploutz-Snyder L, Foley J, Ploutz-Snyder R, Kanaley J, Sagendorf K, Meyer R. Gastric gas and fluid emptying assessed by magnetic resonance imaging. Eur I Appl Physiol 1999; 79: 212-20.

26 Almiron-Roig E, Drewnowski A. Hunger, thirst, and energy intakes following consumption of caloric beverages. Physiol Behav 2003; 5: 767-73. 